Самарского научного центра Российской академии наук. 2014. Т. 16. № 1-4. С. 1205-1208.

20. Саксонов С.В., Иванова А.В., Силаева Т.Б., Соловьева В.В., Раков Н.С., Ильина В.Н. Флора озера Молочка и его ближайших окрестностей в Самарской области (Высокое Заволжье, Сокский флористический район) // Фиторазнообразие Восточной Европы. 2007. № 2. С. 77-98.

21. Красная книга Российской Федерации (растения и грибы). М., 2008. 855 с.

22. Красная книга Самарской области / под редакцией Г.С. Розенберга, С.В. Саксонова. Т. 1. Редкие виды растений, лишайников и грибов. Тольятти, 2007. 372 c.

23. Ключевые орнитологические территории России. Т. 1. Ключевые орнитологические территории международного значения в Европейской России. М.: Союз охраны птиц России, 2000. 702 с.

24. Саксонов С.В., Сенатор С.А. Территории особого природоохранного значения Самарской области // Изумрудная книга Российской Федерации. Территории особого природоохранного значения Европейской России. Предложения по выявлению. Ч. 1. М.: Институт географии РАН, 2011-2013. С. 129-133.

Статья подготовлена в рамках проекта Программы развития ООН и Европейской Комиссии "Охрана и устойчивое использование торфяников в Российской Федерации с целью снижения эмиссии $\mathrm{CO}_{2}$ и содействия в адаптации экосистем к изменениям климата» и, отчасти, поддержана грантом РФФИ № 14-04-97072 р_Поволжье а.

\title{
THE NECESSITY OF SAMARA REGION WETLANDS PROTECTION
}

\section{(C) 2016}

I.V. Kazantsev, candidate of biological sciences, dean of the Faculty of Natural Sciences and Geography Samara State University of Social Sciences and Education, Samara (Russia)

S.A. Senator, candidate of biological sciences, senior researcher of the Laboratory of Problems of Phytodiversity Institute of Ecology of the Volga River Basin of the Russian Academy of Sciences, Togliatti (Russia)

Abstract. The article deals with the issue of the need to preserve the wetlands of Samara region. Occupying a small area and being on the southern border of its distribution, all available on the territory of Samara region marshes are considered to be valuable environmental systems in environmental, hydrological, landscape and biogeographic relationships. The main threats to wetland ecosystems are investigated, including the quality and characteristics of local peat, the failure of security mode, the absence of regional legislation regulating environmental management in wetlands. The authors study a list of plants growing on the territory of the wetland nature monuments in Samara region and being of particular environmental and phytogeographical interest. Data about the most valuable marshes of Samara region under the protection or need of saving are given: Hipnovoe swamp, Muranskie lakes, Racheyskay taiga, Bolshoe Orlovo, Bolshaya and Malaya Trostyanka, Kesme, Zolotushnoe, Svetloe Ozero, Berezovay Polyna, Sharlyk, Belokluchenskoe, Mohovoe swamp, Mohovoe II, Chekalinskoe swamp, Trostnikovoe, Molochka lake, Uzilovo swamp, Bychye swamp. Each of the swamps is given a geographical reference, its footprint, status and rationale of the organization of the protection regime. The main threats for wetlands in the region are consideration of peat deposits as a potential source of raw materials for medical purposes and organic fertilizer and, in some cases, compliance with the established regime of protection and the absence of regional legislation regulating environmental management in wetlands.

Keywords: wetlands; peat; marsh ecosystems; conservation value; rare species of plants; recommendations for conservation; forest-steppe and steppe zone; South-East of European Russia; Samara region; Hipnovoe swamp; Muranskie lakes; Racheyskay taiga; Bolshoe Orlovo; Bolshaya and Malaya Trostyanka; Kesme; Zolotushnoe; Svetloe Ozero; Berezovay Polyna; Sharlyk; Belokluchenskoe; Mohovoe swamp; Mohovoe II; Chekalinskoe swamp; Trostnikovoe; Molochka lake; Uzilovo swamp; Bychye swamp.

УДК $574.3 ; 57.026$

\section{ОПОСРЕДОВАННАЯ КОММУНИКАЦИЯ И ЗАВИСИМОСТЬ ПОВЕДЕНЧЕСКОЙ АКТИВНОСТИ ЕНОТОВИДНОЙ СОБАКИ (NYCTEREUTES PROCYONOIDES GRAY, 1834) ОТ ПОГОДНЫХ УСЛОВИЙ}

(C) 2016

Е.С. Камалова, аспирант кафедры экологии, ботаники и охраны природы Самарский национальный исследовательский университет имени академика С.П. Королёва, Самара (Россия)

Аннотация. В Самарской области енотовидная собака является инвазийным видом. В настоящее время этот вид встречается в северных, северо-западных и западных районах Самарской области, наиболее широко распространен в районе Васильевских островов, села Рождествено, в пойменных участках национального парка «Самарская Лука». По мнению некоторых авторов, этот вид способен нанести вред охотничьим хозяйствам, поскольку влияет на численность водоплавающих птиц. В Самарской области воздействие этого хищника на охотничьи виды не отмечалось, однако необходимо всестороннее изучение поведения, распространения, экологии вида и его влияния на исконные экосистемы. В данной статье приведены результаты исследования опосредованной коммуникации енотовидной собаки с использованием метода детального тропления зимних наследов животных в национальном парке «Самарская Лука» в снежный период года с 2009 по 2015 гг. Пред- 
ставлена динамика коммуникативного поведения енотовидной собаки с 2009 по 2015 гг. Одним из основных факторов, влияющих на поведение, является высота снежного покрова. Для детального анализа применялся параметр жесткости погодных условий по Бодману, учитывающий температуру воздуха и скорость ветра. Приведены данные по полоспецифическим особенностям в поведении и зависимости поведенческой активности от погодных условий.

Ключевые слова: енотовидная собака; Nyctereutes procyonoides; опосредованная коммуникация; внутривидовая коммуникация; маркировка; детальное тропление; биологическое сигнальное поле; поведенческая активность; элементарная двигательная реакция; интродуцент; адаптация; снежный покров; коэффициент суровости погоды по Бодману; Самарская Лука; пойменные территории.

Введение. Енотовидная собака является видоминтродуцентом, сравнительно недавно расселившимся в пределах Самарской области. Работы по акклиматизации проводились на территории области с 1934 г. [1; 2, 3] Данный вид экологически пластичен и достаточно быстро адаптируется к условиям, отличным от таковых в исконном ареале [4]. С 80-х гг. прошлого столетия енотовидная собака была обнаружена в ООПТ Самарской области [5; 6]. На данный момент вид распространен на пойменных участках национального парка «Самарская Лука», кроме того, регистрируются единичные встречи зверьков в Жигулёвском заповеднике [7], хотя и отмечается тяготение этих животных к околоводным биотопам $[4 ; 8,9$, 10]. По мнению некоторых авторов $[11 ; 12]$, енотовидная собака способна нанести вред охотничьим хозяйствам, поскольку влияет на численность водоплавающих птиц. Хотя в Самарской области влияние данного хищника на охотничьи виды не отмечалось, необходимо всестороннее изучение экологии любого вида-вселенца, его поведения, распространения и особенностей освоения им новой среды обитания, особенно в случае заселения видом охраняемых природных территорий. Важным аспектом таких исследований является изучение коммуникативного и маркировочного поведения вида. Эти исследования позволят проследить успешность акклиматизации вида на осваиваемой территории, оценить процесс его включения в структуру и функционирование экосистем Самарской области. Анализ внутри- и межвидовой коммуникации млекопитающих - необходимый этап изучения зооценозов.

Опосредованная коммуникация играет важную роль в жизни хищных млекопитающих, так как данный вид взаимодействия особей позволяет поддерживать границы индивидуальных территорий, помогает в поиске особей другого пола в период размножения и определяет распределение особей в пространстве [13]. Поскольку енотовидная собака не имеет другой охраняемой территории, кроме убежища и окружающего его участка, территориальное поведение у этого хищника выражено слабее, чем у других псовых [4]. Внутривидовая коммуникация в основном выражается в мягких формах (не требующих проявления агрессии): маркировка, реагирование на объекты, несущие информацию о других особях популяции. [13].

Целью данного исследования явилось изучение опосредованной коммуникации енотовидной собаки и выявление зависимости поведенческой активности вида от погодных условий на примере Самарской области. Были поставлены следующие задачи: сравнить поведенческую активность в годы с разными погодными условиями, исследовать полоспецифические особенности в коммуникации, проследить изменения во внутривидовом поведении енотовидной собаки с 2009 по 2015 гг.

Территория исследования. Полевые исследования проводились на территории государственного природного национального парка «Самарская Лука» в Мордовинской пойме (на острове Мордово и в местности северо-западнее села Мордово вдоль протоки Кольцовская Воложка) и в окрестностях села Малая Рязань. Местность имеет увалисто-волнистый рельеф. Площадь острова Мордово составляет примерно

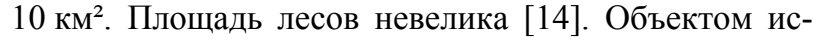
следований являются особи енотовидной собаки, обитающие на территории национального парка «Самарская Лука» в Мордовинской пойме и вблизи с. Малая Рязань. Для изучаемого вида не требуются особые условия среды, но животные преимущественно селятся вблизи водоёмов в местах, покрытых густой растительностью [15].

Meтоды исследований. Полевые исследования проводились в снежный период года с 2009 по 2015 гг. по методике детального тропления зимних наследов животных, основанной на концепции биологического сигнального поля, доработанной Д.П. Мозговым [16; 17]. Енотовидная собака - единственный представитель семейства псовых, способный впадать в состояние зимнего сна, продолжительность которого варьирует от погоды и упитанности животного [18]. В условиях национального парка «Самарская Лука» зимний сон исследуемых животных начинается в конце ноября - начале декабря, что совпадает со временем появления устойчивого снежного покрова [15]. С конца декабря по начало февраля наблюдаются лишь единичные следовые дорожки, незначительной протяженности. Поэтому проводить тропления енотовидной собаки в декабре и январе не представляется возможным. Активный выход зверьков приходится на конец февраля [19]. Часто наблюдается многоследье, поскольку животные могут перемещаться по территории парами или даже группой, тогда на одном участке находится много следовых дорожек особей, иногда объединяющихся в общие тропы, что затрудняет тропление, так как выделить отдельный след практически невозможно.

Результаты и их обсуждение. В экологических исследованиях зачастую требуется учет как можно большего количества условий. Показатель жесткости погодных условий по Бодману позволяет учитывать температуру воздуха и скорость ветра. Показатель (в баллах) высчитывается по формуле:

$$
\mathrm{S}=(1-0,04 \mathrm{t})(1+0,272 \mathrm{~V}),
$$

где $\mathrm{S}$ - баллы суровости; $\mathrm{t}$ - средняя температура воздуха, ${ }^{\circ} \mathrm{C} ; \mathrm{V}$ - средняя скорость ветра, м/с.

Известно, что при разной скорости ветра ощущение организмом температуры воздуха меняется, по- 
скольку ветер усиливает теплопотери. Для расчета показателя жесткости были взяты данные измерений температуры воздуха и скорости ветра ближайшей к месту тропления метеостанции (Безенчук, метеостанция (WMO ID 27995) [20]. При попытке расчета изменений погодных условий с учетом показателя суровости погоды по Бодману мы обнаружили, что, несмотря на некоторые флуктуации суровости в отдельные недели троплений, средний балл был одинаков для двух приводимых периодов и составлял 2,10. Однако существенно различалась величина снежного покрова (для 2013 г. в среднем составила 40,55 см и 70,38 см - для 2012 г.). Таким образом, 2012 год является многоснежным, а 2013 год - малоснежным.

При исследовании поведения енотовидных собак все реакции были представлены в виде элементарных двигательных актов $[17 ; 21]$. В ряде литературных источников указывается на возможность представления собранного материала в виде пересчета данных на величину эквивалентной дистанции, на 100 реакций и на 1000 метров [9; 21]. В ходе работы мы решили провести анализ данных из расчета на 100 реакций. Это позволило нам сравнить изменение поведенческой активности за два года с разным показателем снежности. Результаты представлены в табл. 1.

Сравнение поведенческой активности енотовидной собаки показало уменьшение числа реагирований на объекты внутривидовой коммуникации в многоснежный год. Это объясняется тем, что большинство реакций внутривидовой коммуникации было направлено на тропы особей своего вида. Тропы, особенно одиночные следы, достаточно недолговечны, поскольку быстро заносятся снегом при обильных осадках.

Кроме того, наблюдается снижение маркировочной активности енотовидной собаки в многоснежный период. Это можно объяснить особенностями морфологии вида, поскольку эти животные обладают относительно короткими лапами, что затрудняет передвижение по глубокому снегу. Кроме того, в единичных случаях определение мочевой точки при троплении затрудняется в связи со снежными заносами. Зачастую следовой рисунок указывает на наличие мочевой точки, но саму метку различить невозможно.

Снижение маркировочной активности наблюдается в поведении и самцов и самок. Особенно четко эти изменения наблюдаются у самцов енотовидной собаки. Это можно объяснить тем, что они часто оставляют метки на периферии территории, тогда как самки проявляют маркировочные реакции в основном вблизи троп особей своего вида. Поскольку передвижение по глубокому снегу затруднено, то и оставление меток самцами вдали от общих троп уменьшилось.

В многоснежный период возрастает число перемещений енотовидной собаки по тропам других животных, а также общим тропам, тропинкам и дорогам человека, следам автомобилей и снегоходов, лыжням. Это связывается с экономией энергии при перемещении по утоптанному снегу [22]. Количество ориентировочных реакций увеличилось и у самцов, и у самок. Особи чаще проявляют такие реакции при осмотре территории и поиске оптимального маршрута.
Было проведено сравнение внутривидовой коммуникации енотовидной собаки с 2009 по 2015 гг. Для сравнения выбрали отношение количества реагирований животных на объекты коммуникативного характера к общему числу реагирований. Результаты сравнения представлены на рисунке 1.

Таблица 1 - Сравнительный анализ поведенческой активности енотовидной собаки в зависимости от величины снежного покрова в расчете на 100 реакций

\begin{tabular}{|c|c|c|c|c|c|}
\hline \multirow[b]{2}{*}{$\begin{array}{c}\text { № } \\
\Pi / \Pi\end{array}$} & \multirow{2}{*}{$\begin{array}{l}\text { Наимено- } \\
\text { вание } \\
\text { типов } \\
\text { реакций }\end{array}$} & \multirow[b]{2}{*}{ 今 } & \multicolumn{3}{|c|}{$\begin{array}{c}\text { Пересчет на } 100 \text { реакций } \\
\text { (на } 100 \%)\end{array}$} \\
\hline & & & $\begin{array}{c}\text { Ма- } \\
\text { лоснеж } \\
\text { ный } \\
\text { период }\end{array}$ & $\begin{array}{c}\text { Мно- } \\
\text { госнеж- } \\
\text { ный } \\
\text { период }\end{array}$ & $\begin{array}{c}\text { Тенден- } \\
\text { ция }\end{array}$ \\
\hline \multirow{2}{*}{1} & \multirow{2}{*}{$\begin{array}{l}\text { Общая сумма } \\
\text { двигательных } \\
\text { реакций }\end{array}$} & q & 24,18 & 22,22 & $\begin{array}{c}\text { уменьши- } \\
\text { лось }\end{array}$ \\
\hline & & $\hat{0}$ & 9,28 & 23,66 & возросло \\
\hline \multirow{2}{*}{2} & \multirow{2}{*}{$\begin{array}{l}\text { Ориентирово- } \\
\text { чные реакции }\end{array}$} & q & 1,10 & 3,03 & возросло \\
\hline & & $\hat{\sigma}$ & 0,30 & 2,84 & возросло \\
\hline \multirow{2}{*}{3} & \multirow{2}{*}{$\begin{array}{l}\text { Исследова- } \\
\text { тельские } \\
\text { реакции }\end{array}$} & 우 & 1,65 & 6,06 & возросло \\
\hline & & $\hat{\sigma}$ & 5,69 & 4,10 & $\begin{array}{c}\text { уменьши- } \\
\text { лось }\end{array}$ \\
\hline \multirow{2}{*}{4} & \multirow{2}{*}{$\begin{array}{l}\text { Пассивно- } \\
\text { оборонитель- } \\
\text { ные реакции }\end{array}$} & q & 3,30 & 8,08 & возросло \\
\hline & & $\hat{0}$ & 0,90 & 0,95 & возросло \\
\hline \multirow{2}{*}{5} & \multirow{2}{*}{$\begin{array}{l}\text { Коммуника- } \\
\text { ция (внутри- } \\
\text { видовая + } \\
\text { межвидовая) }\end{array}$} & q & 12,09 & 12,12 & возросло \\
\hline & & $\hat{\sigma}$ & 9,88 & 7,57 & $\begin{array}{c}\text { уменьши- } \\
\text { лось }\end{array}$ \\
\hline \multirow{2}{*}{6} & \multirow{2}{*}{$\begin{array}{l}\text { Внутри- } \\
\text { видовая } \\
\text { коммуника- } \\
\text { ция }\end{array}$} & q & 10,99 & 9,09 & $\begin{array}{c}\text { уменьши- } \\
\text { лось }\end{array}$ \\
\hline & & $\hat{0}$ & 5,99 & 5,05 & $\begin{array}{c}\text { уменьши- } \\
\text { лось }\end{array}$ \\
\hline \multirow{2}{*}{7} & \multirow{2}{*}{$\begin{array}{l}\text { Подражате- } \\
\text { льные реак- } \\
\text { ции (переме- } \\
\text { щение по дру- } \\
\text { гим следам) } \\
\end{array}$} & q & 3,85 & 5,05 & возросло \\
\hline & & $\hat{0}$ & 4,49 & 5,05 & возросло \\
\hline \multirow{2}{*}{8} & \multirow{2}{*}{ Маркировка } & q & 21,43 & 21,21 & $\begin{array}{c}\text { уменьши- } \\
\text { лось }\end{array}$ \\
\hline & & $\hat{o}$ & 35,93 & 32,18 & $\begin{array}{c}\text { уменьши- } \\
\text { лось }\end{array}$ \\
\hline \multirow{2}{*}{9} & \multirow{2}{*}{$\begin{array}{l}\text { Реакции } \\
\text { комфорта }\end{array}$} & q & 6,04 & 0,00 & $\begin{array}{c}\text { уменьши- } \\
\text { лось }\end{array}$ \\
\hline & & $\hat{o}$ & 0,00 & 0,00 & $\begin{array}{c}\text { не изме- } \\
\text { нилось }\end{array}$ \\
\hline \multirow{2}{*}{10} & \multirow{2}{*}{$\begin{array}{l}\text { Реакции } \\
\text { дискомфорта }\end{array}$} & q & 1,10 & 0,00 & $\begin{array}{c}\text { уменьши- } \\
\text { лось }\end{array}$ \\
\hline & & $\hat{\sigma}$ & 0,00 & 0,32 & возросло \\
\hline
\end{tabular}


Видно, что резкое возрастание величины снежного покрова повлекло за собой снижение внутривидовой коммуникации приблизительно на $10 \%$, что можно объяснить увеличением количества ориентировочных и пассивно-оборонительных реакций. При снижении показателя снежности происходит постепенный рост доли коммуникативных реакций.

Таким образом, наблюдается зависимость поведенческой активности енотовидной собаки от величины снежного покрова, что связано с морфологическими параметрами и экологией вида.

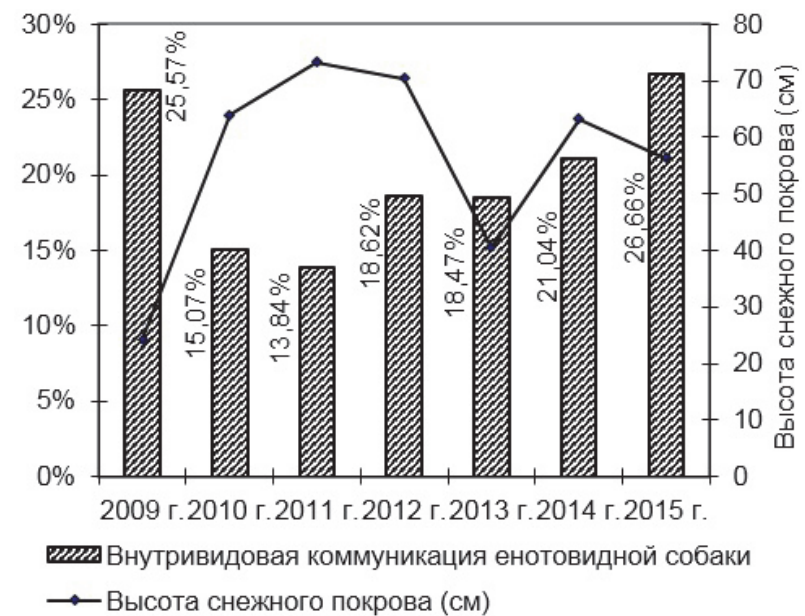

Рисунок - 1 Динамика реагирования енотовидных собак на объекты внутривидовой коммуникации по отношению к общему числу реагирований (в \%) и изменение высоты снежного покрова (на примере Мордовинской поймы)

\section{СПИСОК ЛИТЕРАТУРЫ:}

1. Бобров В.В., Варшавский А.А., Хляп Л.А. Чужеродные виды млекопитающих в экосистемах России / ред. Ю.Ю. Дгебуадзе, В.М. Неронов. М.: Товарищество научных изданий КМК, 2008. 232 с.

2.Колосов А.М., Лавров Н.П. Обогащение промысловой фауны СССР. М.: Лесная промышленность, $1968.256 \mathrm{c}$.

3. Шапошников В.М. Реконструкция фауны промысловых животных в лесных биогеоценозах в пределах лесной и лесостепной зон Куйбышевской области // Вопросы лесной биогеоценологии, экологии и охраны природы в степной зоне. Вып. 2. Куйбышев: Куйбышевский госуниверситет, 1977. С. 86-91.

4. Насимович А.А. Енотовидная собака // Песец, лисица, енотовидная собака. М.: Наука, 1985. С. 116159.

5. Вехник В.П. Критические замечания к фаунотаксономическому составу млекопитающих Самарской Луки // Биологическое разнообразие заповедных территорий: оценка, охрана, мониторинг: Сб. науч. тр. Самара, 2000. С. 310-317.

6. Горелов М.С. Обзор териофауны Правобережья и Самарского Заволжья и некоторые особенности ее формирования // Самарская Лука: Бюллетень. 1991. № 1. C. 63-78.

7. Камалова Е.С., Фокина М.Е. Освоение новой среды обитания енотовидной собакой (Nyctereutes procyonoides) и изменение значимости объектов коммуникативного характера с 1995 по 2012 гг. на примере Мордовинской поймы национального парка
«Самарская Лука» // Биологическое сигнальное поле млекопитающих: колл. монография / под ред. А.А. Никольского, В.В. Рожнова. М.: Товарищество научных изданий КМК, 2013. С. 116-120.

8. Ружиленко Н.С. Пространственное распределение и особенности поселения енотовидной собаки Nyctereutes procyonoides на островных территориях Кременчугского водохранилища // Териофауна России и сопредельных территорий. VII съезд Териол. общества: Материалы международного совещ. М., 2003. C. 298-299.

9. Фокина М.Е. Анализ информационно-знаковых полей енотовидной собаки (Nyctereutes procyonoides Gray) и лисицы обыкновенной (Vulpes vulpes L.) (на примере национального парка «Самарская Лука»): дис. ... канд. биол. наук. Самара, 2006. 153 с.

10. Юдин В.Г. Енотовидная собака Приморья и Приамурья. М.: Наука, 1977. 161 с.

11. Бурко Л.Д., Гричик В.В. Позвоночные животные Беларуси: Учебное пособие. Мн.: БГУ, 2003. C. 373.

12. Дулицкий А.И. Млекопитающие Крыма. Симферополь: Крымское уч.-пед. изд-во, 2001. 224 с.

13. Рожнов В.В. Опосредованная коммуникация млекопитающих: о смене парадигмы и новом концептуальном подходе в исследовании маркировочного поведения // Зоологический журнал. 2004. Т. 83, № 2. C. $132-157$.

14. Природа Самарской Луки: учебное пособие / Е.Г. Бирюкова, М.С. Горелов, Л.А. Евдокимов и др. Куйбышев: Куйб. пед. ин-т, 1986. 88 с.

15. Фокина М.Е. Енотовидная собака (Nyctereutes procyonoides Gray) Самарской области // Вестник охотоведения. 2007. Т. 4, № 2. С. 124-129.

16. Наумов Н.П. Биологические (сигнальные) поля и их значение в жизни млекопитающих // Успехи современной териологии. М.: Наука, 1977. С. 93-110.

17. Мозговой Д.П. Информационно-знаковые поля млекопитающих: теория и практика полевых исследований: дис. в форме научного доклада. Самара: Универс-групп, 2005. 50 c.

18. Калабухов Н.И. Спячка млекопитающих. М.: Наука, 1985. 264 с.

19. Камалова Е.С. Изменение внутривидового коммуникативного и маркировочного поведения енотовидной собаки (Nyctereutes procyonoides) на территории Мордовинской поймы национального парка «Самарская Лука» в период с 2009 по 2012 гг. // Биологическое сигнальное поле млекопитающих: Колл. монография / под ред. А.А. Никольского, В.В. Рожнова. М.: Товарищество научных изданий КМК, 2013. C. $109-115$.

20. Архив погоды в Безенчуке [Электронный реcypc] // http://rp5.ru/Архив_погоды_в_Безенчуке.

21. Склюев В.В. Популяционный анализ лисицы обыкновенной (Vulpes vulpes) в биотопах Самарской области разной степени нарушенности: дис. ... канд. биол. наук. Самара, 2010. 220 c.

22. Камалова Е.С., Лапузина В.В. Особенности внутривидовой коммуникации енотовидной собаки (Nyctereutes procyonoides) // Териофауна России и сопредельных территорий: Международное совещание (IX Съезд Териологического общества при РАН). М.: Товарищество научных изданий КМК, 2011. С. 195. 


\section{MEDIATED COMMUNICATION AND DEPENDENCE BEHAVIORAL ACTIVITY OF RACCOON DOG (NYCTEREUTES PROCYONOIDES GRAY, 1834) ON WEATHER CONDITIONS}

(C) 2016

E.S. Kamalova, postgraduate student of the Chair of Ecology, Botany and Nature Protection Samara National Research University, Samara (Russia)

Abstract. The raccoon dog is an invasive species in the Samara region. At present, this species is founded in the northern, north-western and western territories of the Samara region, and the most widely spread on Vasilyevsky Islands, near the Rozhdestveno village, in floodplain areas of the national park «Samarskaya Luka». According to some authors' data, this species may be able to be cause damage to game species, due to it's impact on the number of waterfowl. In the Samara region the impact of this predator on hunting species are not mentioned, but a comprehensive study of the behavior, distribution, ecology of the species and its impact on native ecosystems are required. This article describes a study on raccoon dog's mediated communication which was carried out by detailed method of tracking animals' winter footprints in the national park «Samarskaya Luka» in the snow season at 2009-2015. The dynamics of communicative behavior of raccoon dog at 2009-2015 is presented. One of the main factors influencing on animal's behavior is a snow cover. For the detailed analysis Bodman's index of weather rigidity was applied, using data of the air temperature and wind speed. The data which show differences in behavioral activity of raccoon dog's males and females depending on the weather conditions are presented.

Keywords: raccoon dog; Nyctereutes procyonoides; mediated communication; intraspecific communication; marking behavior; detail footprints tracking; biological signaling field; behavioral activity; elementary motor act; invasive species; adaptation; snow cover; Bodman index; Samarskaya Luka; floodplain areas.

УДК 0058 01/.07+00502.75

\section{ПРЕДВАРИТЕЛЬНЫЕ ИТОГИ МОНИТОРИНГА БИОЭКОЛОГИЧЕСКИХ ОСОБЕННОСТЕЙ РАСТЕНИЙ РЯБЧИКА РУССКОГО (FRITILLARIA RUTHENICA WIKSTR.) В МОДЕЛЬНЫХ БИОТОПАХ КРАСНОСАМАРСКОГО ЛЕСНИЧЕСТВА} (C) 2016

М.Г. Котельникова, аспирант кафедры экологии, ботаники и охраны природы Самарский национальный исследовательский университет имени академика С.П. Королёва, Самара (Россия)

Aннотация. В статье представлены предварительные итоги мониторинга растений рябчика русского (Fritillaria ruthenica Wikstr.), относящегося к категории редких и исчезающих видов растений, включенного в Красную Книгу России и Самарской области. Путем обобщения доступных источников нами составлена общая характеристика морфологических и биоэкологических особенностей растения. В 2012-2014 гг. было проведено исследование рябчика в Красносамарском лесничестве, полученные данные использовали для установления морфометрических показателей растений рябчика русского, оценки уровня их изменчивости и сопоставления с указанными в литературе для данного растения количественными признаками. Было установлено, что длина побегов у растений рябчика русского в обследованном модельном биотопе Красносамарского леса в 2012 2014 гг. изменялась в интервале 20 .. 70 см, в 2012 и 2013 гг. преобладали особи с длиной побега около 50 см, в 2014 г. - около 50 и 60 см. Признак длины побега характеризуется пластичностью, наибольший уровень варьирования отмечен в 2013 г. Значения длины побегов вписываются в диапазон, указанный для различных частей ареала в литературе, при значительной доле «высоких» растений в обследованной популяции. Это может свидетельствовать о благоприятности условий произрастания и возможности сохранения в составе растительных сообществ при отсутствии лимитирующих антропогенных факторов.

Ключевые слова: Fritillaria ruthenica Wikstr; морфологические и биоэкологические особенности; количественные и качественные характеристики; длина побега; Красносамарское лесничество; модельный биотоп; Самарская область.

Самарская (Куйбышевская) область относится к числу интереснейших регионов Восточно-Европейской равнины. На территории данной равнины было несколько оледенений, но ни одно из них не затронуло Самарскую область, что позволило сохранить до наших дней популяции многих реликтовых растений, во флоре области представлены эндемичные виды различного статуса. Долговременные изменения природных условий стали причиной сокращения лесистости и развития степных пространств, влияние человека в последние эпохи ускорило сокращение лесопокрытых территорий и еще сильнее - степей, ко- торые подверглись распашке. В современных условиях в районах Самарской области на долю агроэкосистем приходится от 50 до 90\%, сохранившиеся фрагменты природных экосистем подвергаются сильному антропогенному воздействию [1]. На данный момент во флоре области насчитывается 258 редких и исчезающих видов растений [2], в этих условиях изучение биологических особенностей редких растений приобретает особую важность для их сохранения. Наша статья посвящена рассмотрению биоэкологических особенностей рябчика русского Fritillaria ruthenica Wikstr. - редкого вида, внесенно- 